\title{
0007 COMMUNITY-BASED STUDY OF RISK AND PROTECTIVE FACTORS OF ELDER ABUSE AND NEGLECT IN NIGERIA
}

I S Abdulraheem* Correspondence: Department of Epidemiology and Community Health, College of Medicine, University of Ilorin, Ilorin 240001, Nigeria

10.1136/ip.2010.029215.7

Background There is a dearth of literature on elderly abuse and neglect in Nigeria. Improving our understanding of the risk and protective factors for elder abuse and neglect will help predict situations where abuse or neglect is likely to occur. It will also increase our understanding of factors that build resilience or ameliorate situations that may otherwise result in abuse or neglect.

Objective The objectives of this study were to ascertain the factors that may increase the risk of abuse or neglect and protective factors that may prevent abuse or neglect from occurring or recurring.

Methodology Qualitative sampling methods were used to collect data about elder abuse and neglect from members of various ethnic groups in selected Nigerian communities, some of whom had experienced elder abuse. Methods of data collection were face-to-face, focus group and telephone interviews. Interview guides were developed after consultation and reviewing of the literature.

Result Multiple factors like poverty, increase cost of living, moral decadence, degeneration of cultural norms and values, intergenerational transfer of wealth, urbanisation and modernisation are contributory factors. Free social services are protective.

Conclusion It is being recommended that there is need for Nigerian government to initiate the establishment of legal policies and structures that ensure the protection of the rights of all citizens while being especially sensitive to the rights of the older persons and other vulnerable sections of the community. 